\section{Anionenlücke im Plasma}

O. Müller-Plathe

Hamburg, Deutschland

\section{Englischer Begriff anion gap}

Definition Die Anionenlücke im Serum oder Plasma ist die Konzentrationsdifferenz zwischen dem wichtigsten Kation (Natrium) und der Summe der beiden wichtigsten Anionen (Chlorid und Bicarbonat):

$$
\text { Anionenlücke }(\mathrm{mmol} / \mathrm{L})=c \mathrm{Na}^{+}-\left(c \mathrm{Cl}^{-}+c \mathrm{HCO}_{3}{ }^{-}\right)
$$

Beschreibung Der Ausdruck Anionenlücke darf nicht als ein Fehlen von Anionen missverstanden werden. Nach dem Gesetz der Elektroneutralität entsprechen kationische und anionische Ladung einander in jeder Situation. Die Zunahme normalerweise nicht gemessener Anionen bzw. organischer Säuren geht daher bei unverändertem Kationenbestand mit einer Abnahme von Bicarbonat und Chlorid einher und ver- größert somit die Anionenlücke. Zur Veranschaulichung s. Ionogramm des Plasmas im Stichwort $>$ Wasserhaushalt.

Die Anionenlücke beträgt normalerweise $8-16 \mathrm{mmol} / \mathrm{L}$. Erhöhte Werte bei metabolischer Acidose ( $>$ Acidose, metabolische) durch erhöhte Konzentration organischer Anionen wie bei der Laktatacidose und Ketoacidose ( $>\beta$-Hydroxybutyrat, $>$ Acetoacetat), ferner durch Zunahme von Sulfat und Phosphat bei global-renaler Acidose (nicht jedoch bei renaltubulärer Acidose) und durch diverse Säureradikale bei Vergiftungen. Erniedrigte Werte bei ausgeprägter Verminderung anionischer Proteine (Hypalbuminämie) und Hämodilution. Die diagnostische Brauchbarkeit der Anionenlücke ist nur bei sehr exakter Elektrolytanalytik gegeben.

\section{Literatur}

Morimatsu H, Rocktaschel J, Bellomo R et al (2003) Comparison of point-of-care versus central laboratory measurement of electrolyte concentrations on calculations of the anion gap and the strong ion difference. Anesthesiology 98:1077-1084 